\title{
Preoperative Management of Antiplatelet Agents for CABG Surgery Patients: A Prospective Cohort Study Focused on P2Y12 Inhibitors
}

\author{
Mohammad Miah, Syeda Nafisa, Liam Phelan, Sandeep Kaur, Mostafa Mehann, Ahmed Ashoub \\ Queen Elizabeth Hospital Birmingham, Birmingham, UK \\ Email: mohammad.miah1@nhs.net
}

How to cite this paper: Miah, M., Nafisa, S., Phelan, L., Kaur, S., Mehann, M. and Ashoub, A. (2020) Preoperative Management of Antiplatelet Agents for CABG Surgery Patients: A Prospective Cohort Study Focused on P2Y12 Inhibitors. Open Access Library Journal, 7: e6196.

https://doi.org/10.4236/oalib.1106196

Received: February 28, 2020

Accepted: April 21, 2020

Published: April 24, 2020

Copyright (๑) 2020 by author(s) and Open Access Library Inc.

This work is licensed under the Creative Commons Attribution International License (CC BY 4.0).

http://creativecommons.org/licenses/by/4.0/

\begin{abstract}
Dual antiplatelet therapy (DAPT) using aspirin and ticlopidine, a thienopyridine P2Y12 inhibitor, was introduced, decreasing the rate of stent thrombosis to about $1 \%$. Continuation of dual antiplatelet therapy (DAPT) until Coronary artery bypass graft $(\mathrm{CABG})$ increases the risk of excessive perioperative bleeding, transfusions, and re-exploration for bleeding as shown in RCTs observational studies and metanalyses. Therefore, it is recommended that the $\mathrm{P} 2 \mathrm{Y} 12$ inhibitor should be discontinued whenever possible before elective CABG. For clopidogrel, it was shown in the CABG sub-study of the CURE trial that discontinuation $\geq 5$ days before CABG did not increase the risk of bleeding complications. For prasugrel, a longer time interval (7 days) is recommended due to the longer offset time compared to clopidogrel. In a single institution Dutch registry encompassing 705 consecutive patients who underwent isolated on-pump CABG, ticagrelor discontinuation $>72 \mathrm{~h}$ and clopidogrel discontinuation $>120 \mathrm{~h}$ before surgery were not associated with an increased risk of bleeding-related complications. Prospective data were collected on 150 consecutive patients who were admitted with ACS (Acute coronary syndrome) for CABG from $1^{\text {st }}$ October 2017 onwards. Elective admissions for CABG were excluded. There was a significant delay in between stopping and the day of Surgery in multiple patients. There were 25 patients who were admitted with ACS for CABG and they were without clopidogrel for more than 10 days, 20 patients stayed without Ticagrelor preoperatively. From this study, it was evident that the guideline was partially met. Appropriate stopping of P2Y12 inhibitors should be considered before surgery according to the guidelines to achieve successful perioperative haemostasis.
\end{abstract}




\section{Subject Areas}

Clinical Trials, Gastroenterology \& Hepatology, Translational Medicine

\section{Keywords}

Acute Coronary Syndrome, Coronary Artery Bypass Graft, Dual Antiplatelet Therapy

\section{Background}

Antiplatelet therapy has become the mainstay of clinical management of acute coronary syndrome (ACS). There has been extensive research into both physiological and pathological roles that platelets play in haemostasis and thrombosis for more than half a century. Different classes of antiplatelet agents have been introduced since late 1990s, which include the glycoprotein IIb/IIIa (GPIIb/IIIa) receptor antagonists, and thienopyridine derivatives. Dual antiplatelet therapy (DAPT) using aspirin and ticlopidine, a thienopyridine P2Y12 inhibitor, was introduced, decreasing the rate of stent thrombosis to about $1 \%$. The $2^{\text {nd }}$ generation thienopyridine, clopidogrel is now widely used in the setting of ACS and PCI. Activation of P2Y12 receptor is crucial in sustained platelet aggregation induced by adenosine diphosphate (ADP) at the vascular injury site. The $3^{\text {rd }}$ generation thienopyridine, prasugrel is also a prodrug, but is rapidly activated via single CYP450-mediated oxidation. Ticagrelor is a cyclopentyl-triazolopyrimidine, which reversibly inhibits $\mathrm{P} 2 \mathrm{Y} 12$ receptors in contrast to the covalent bond formation between thienopyridines and ADP binding sites. Continuation of dual antiplatelet therapy (DAPT) until Coronary artery bypass graft (CABG) increases the risk of excessive perioperative bleeding, transfusions, and re-exploration for bleeding as shown in RCTs [1] observational studies [2] [3] and metanalyses [4] [5]. Therefore, it is recommended that the P2Y12 inhibitor be discontinued whenever possible before elective CABG [6] [7]. Alternatively, elective operations may be postponed until the DAPT treatment period is completed. For clopidogrel, it was shown in the CABG sub-study of the CURE trial that discontinuation $\geq 5$ days before CABG did not increase the risk of bleeding complications. For prasugrel, a longer time interval (7 days) is recommended due to the longer offset time compared to clopidogrel [8]. In CABG patients treated pre-operatively with ticagrelor, 5 days of discontinuation was initially recommended. This recommendation was based on pharmacokinetic studies and clinical data from patients with stable CAD [9]. In a single institution Dutch registry encompassing 705 consecutive patients who underwent isolated onpump CABG, ticagrelor discontinuation $>72 \mathrm{~h}$ and clopidogrel discontinuation $>120 \mathrm{~h}$ before surgery were not associated with an increased risk of bleeding-related complications [3]. 


\section{Methods}

In patients on $\mathrm{P} 2 \mathrm{Y} 12$ inhibitors who required to undergo non-emergent cardiac surgery, postponing surgery for at least 3 days after discontinuation of ticagrelor, at least 5 days after clopidogrel, and at least 7 days after prasugrel should be considered [IIa B]. [Source: European Heart Journal. Published: 26 August 2017].

Prospective data were collected on 150 consecutive patients who were admitted with ACS for CABG from $1^{\text {st }}$ October 2017 onwards. Elective admissions for CABG were excluded. Data were collected about the following variables: age, sex, name of P2Y12 inhibitors, date of stopping of P2Y12 inhibitors, date of operation.

\section{Results}

Total number of patients was 150 . Among them 88 were male and 62 were female. The age group was between 33 and 81 years. Clopidogrel was stopped $<5$ days before surgery for 50 patients (Figure 1). Ticagrelor and Prasugrel were paused appropriately. However, there was a significant delay between stopping and the day of Surgery in multiple patients. There were 25 patients who were admitted with ACS for CABG and they were without clopidogrel for more than 10 days, 20 patients stayed without Ticagrelor preoperatively.

\section{Discussion}

Continuing DAPT until the day of surgery increases the risk of bleeding, transfusions and re-exploration for bleeding. Thus, P2Y12-receptor inhibitors are discontinued before elective surgery whenever possible. Alternatively, elective operations can be delayed until the DAPT treatment period is completed. In urgent cases, like in patients with ACS, the risk for thromboembolic episodes (stent thrombosis and MI) while waiting for the effect of the P2Y12-receptor inhibitors to cease must be compared against the risk for perioperative bleeding complications. Extreme high risk patients for thrombotic events, e.g. recent stent implantation, bridging therapy may be considered or surgery may be performed without discontinuation of P2Y12 inhibitors. If bridging is warranted, GPIIb/ GPIIIa inhibitors may be used. However, Cangrelor, a new reversible intravenous P2Y12 inhibitor with an ultrashort half-life, has demonstrated a high rate of maintenance for platelet inhibition and no excessive perioperative bleeding complications [10] [11]. Safe discontinuation intervals differ according to the pharmacodynamics and pharmacokinetic profile of each P2Y12-receptor inhibitor. When P2Y12-receptor inhibitors are discontinued, Aspirin should be continued until the operation.

Discontinuation of Clopidogrel 5 days or more before CABG did not increase the risk for bleeding complications. A longer time interval (7 days) is recommended for Prasugrel due to the longer offset of platelet inhibition and a higher incidence of CABG-related bleeding complications compared with that for Clopidogrel. In patients treated with Ticagrelor, discontinuation of the drug 3 to 


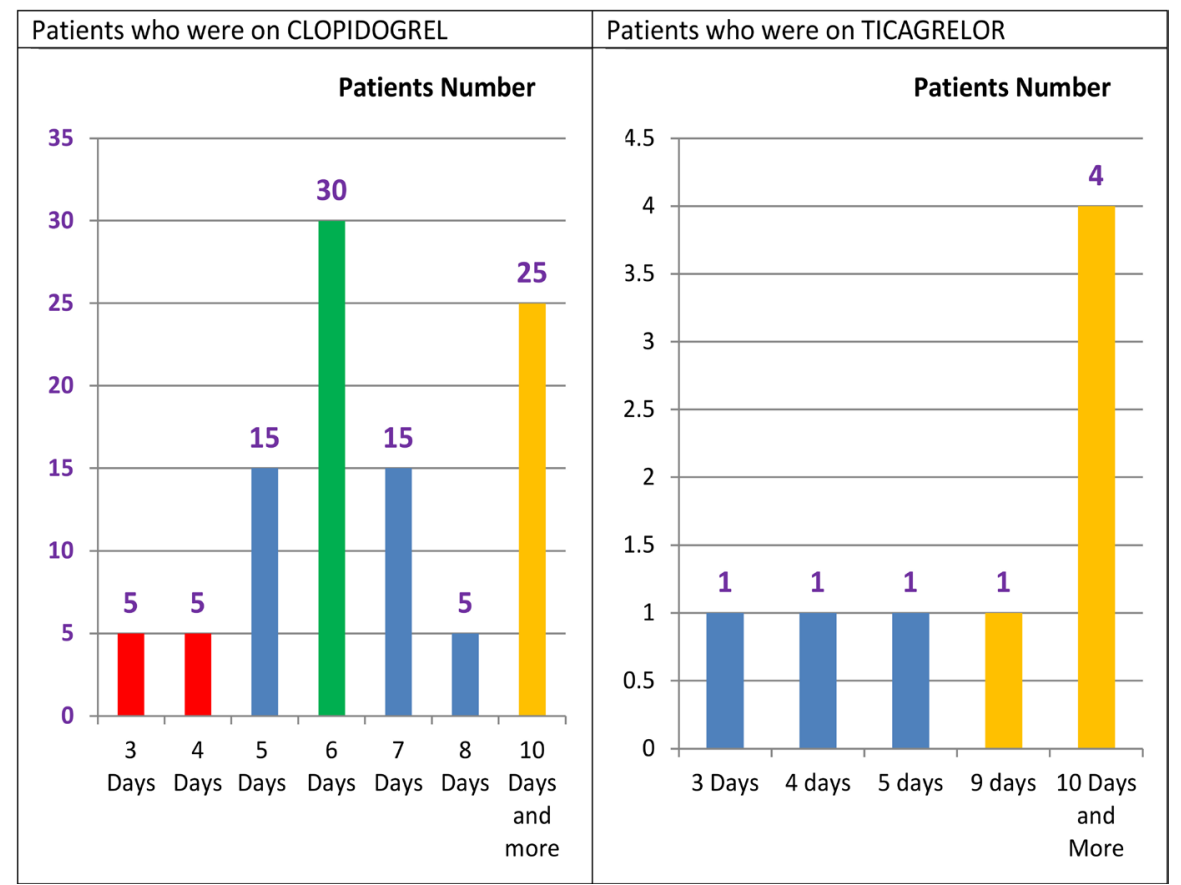

Figure 1. Bar graphs showing the number of patients with their duration on which they were without P2Y12 inhibitors.

4 days, as opposed to 5 days or more before CABG surgery, is not associated with a higher incidence of bleeding complications (OR 0.93; 95\% CI 0.53 - 1.64, $\mathrm{P}=0.80$ ). This finding has been confirmed in multiple studies. In our prospective Cohort study, it was found that some of the patients were without DAPT for an unusually longer period. However, it was not recorded if any of the patients had ACS or not.

\section{Conclusion}

The safe discontinuation interval varies between the different P2Y12 inhibitors due to variations in platelet inhibitory effect and pharmacodynamics and pharmacokinetic properties. From this study, it was evident that the guideline was partially met. Appropriate stopping of P2Y12 inhibitors should be considered before surgery according to the guidelines to achieve successful perioperative haemostasis.

\section{Conflicts of Interest}

The authors declare no conflicts of interest regarding the publication of this paper.

\section{References}

[1] Smith, P.K., Goodnough, L.T., Levy, J.H., Poston, R.S., Short, M.A., Weerakkody, G.J. and Lenarz, L.A. (2012) Mortality Benefit with Prasugrel in the TRITON-TIMI 38 Coronary Artery Bypass Grafting Cohort: Risk-Adjusted Retrospective Data Analysis. Journal of the American College of Cardiology, 60, 388-396. https://doi.org/10.1016/j.jacc.2012.03.030 
[2] Hansson, E.C., Jideus, L., Aberg, B., Bjursten, H., Dreifaldt, M., Holmgren, A., Ivert, T., Nozohoor, S., Barbu, M., Svedjeholm, R. and Jeppsson, A. (2016) Coronary Artery Bypass Grafting-Related Bleeding Complications in Patients Treated with Ticagrelor or Clopidogrel: A Nationwide Study. European Heart Journal, 37, 189-197. https://doi.org/10.1093/eurheartj/ehv381

[3] Tomsic, A., Schotborgh, M.A., Manshanden, J.S.J., Li, W.W.L. and de Mol, B.A.J.M. (2016) Coronary Artery Bypass Grafting-Related Bleeding Complications in Patients Treated with Dual Antiplatelet Treatment. European Journal of Cardio-Thoracic Surgery, 50, 849-856. https://doi.org/10.1093/ejcts/ezw149

[4] Pickard, A.S., Becker, R.C., Schumock, G.T. and Frye, C.B. (2008) Clopidogrel-Associated Bleeding and Related Complications in Patients Undergoing Coronary Artery Bypass Grafting. Pharmacotherapy, 28, 376-392.

https://doi.org/10.1592/phco.28.3.376

[5] Purkayastha, S., Athanasiou, T., Malinovski, V., Tekkis, P., Foale, R., Casula, R., Glenville, B. and Darzi, A. (2006) Does Clopidogrel Affect Outcome after Coronary Artery Bypass Grafting? A Meta-Analysis. Heart, 92, 531-532. https://doi.org/10.1136/hrt.2004.058396

[6] Windecker, S., Kolh, P., Alfonso, F., Collet, J.P., Cremer, J., Falk, V., Filippatos, G., Hamm, C., Head, S.J., Juni, P., Kappetein, A.P., Kastrati, A., Knuuti, J., Landmesser, U., Laufer, G., Neumann, F.J., Richter, D.J., Schauerte, P., Sousa Uva, M., Stefanini, G.G., Taggart, D.P., Torracca, L., Valgimigli, M., Wijns, W. and Witkowski, A. (2014) 2014 ESC/EACTS Guidelines on Myocardial Revascularization: The Task Force on Myocardial Revascularization of the European Society of Cardiology (ESC) and the European Association for Cardio-Thoracic Surgery (EACTS) Developed with the Special Contribution of the European Association of Percutaneous Cardiovascular Interventions (EAPCI). European Heart Journal, 35, 2541-2619.

https://doi.org/10.1093/eurheartj/ehu278

[7] Ferraris, V.A., Saha, S.P., Oestreich, J.H., Song, H.K., Rosengart, T., Reece, T.B., Mazer, C.D., Bridges, C.R., Despotis, G.J., Jointer, K. and Clough, E.R. (2012) Society of Thoracic Surgeons. 2012 Update to the Society of Thoracic Surgeons Guideline on Use of Antiplatelet Drugs in Patients Having Cardiac and Noncardiac Operations. The Annals of Thoracic Surgery, 94, 1761-1781.

https://doi.org/10.1016/j.athoracsur.2012.07.086

[8] Wallentin, L. (2009) P2Y12 Inhibitors: Differences in Properties and Mechanisms of Action and Potential Consequences for Clinical Use. European Heart Journal, 30, 1964-1977. https://doi.org/10.1093/eurheartj/ehp296

[9] Gurbel, P.A., Bliden, K.P., Butler, K., Tantry, U.S., Gesheff, T., Wei, C., Teng, R., Antonino, M.J., Patil, S.B., Karunakaran, A., Kereiakes, D.J., Parris, C., Purdy, D., Wilson, V., Ledley, G.S. and Storey, R.F. (2009) Randomized Double-Blind Assessment of the ONSET and OFFSET of the Antiplatelet Effects of Ticagrelor versus Clopidogrel in Patients with Stable Coronary Artery Disease: The ONSET/OFFSET Study. Circulation, 120, 2577-2585. https://doi.org/10.1161/CIRCULATIONAHA.109.912550

[10] Angiolillo, D.J., Firstenberg, M.S., Price, M.J., Tummala, P.E., Hutyra, M., Welsby, I.J., et al. (2012) Bridging Antiplatelet Therapy with Cangrelor in Patients Undergoing Cardiac Surgery: A Randomized Controlled Trial. JAMA, 307, 265-274. https://doi.org/10.1001/jama.2011.2002

[11] Qamar, A. and Bhatt, D.L. (2016) Current Status of Data on Cangrelor. Pharmacology \& Therapeutics, 159, 102-109. https://doi.org/10.1016/j.pharmthera.2016.01.004 